\title{
Characterization of deletions at $9 p$ affecting the candidate regions for sex reversal and deletion $9 p$ syndrome by MLPA
}

\author{
Michela Barbaro*, ${ }^{*}$ Antonio Balsamo ${ }^{2}$, Britt Marie Anderlid ${ }^{1}$, Anne Grethe Myhre ${ }^{3}$, \\ Monia Gennari $^{2}$, Annalisa Nicoletti ${ }^{2}$, Maria Carla Pittalis ${ }^{4}$, Mikael Oscarson ${ }^{1}$ \\ and Anna Wedell ${ }^{1}$
}

\begin{abstract}
${ }^{1}$ Department of Molecular Medicine and Surgery, Karolinska Institutet, Karolinska University Hospital, Stockholm, Sweden; ${ }^{2}$ Division of Pediatric Endocrinology, Department of Pediatrics, Policlinico S. Orsola-Malpighi, University of Bologna, Bologna, Italy; ${ }^{3}$ Department of Pediatrics, Rikshospitalet, Oslo, Norway; ${ }^{4}$ Department of Obstetrics and Gynecology, Policlinico S. Orsola-Malpighi, University of Bologna, Bologna, Italy
\end{abstract}

The distal region on the short arm of chromosome 9 is of special interest for scientists interested in sex development as well as in the clinical phenotype of patients with the $9 p$ deletion syndrome, characterized by mental retardation, trigonocephaly and other dysmorphic features. Specific genes responsible for different aspects of the phenotype have not been identified. Distal $9 p$ deletions have also been reported in patients with $46, X Y$ sex reversal, with or without $9 p$ deletion syndrome. Within this region the strongest candidates for the gonadal dysgenesis phenotype are the DMRT genes; however, the genetic mechanism is not clear yet. Multiple ligation-dependent probe amplification represents a useful technique to evaluate submicroscopic interstitial or distal deletions that would help the definition of the minimal sex reversal region on $9 p$ and could lead to the identification of gene(s) responsible of the $46, X Y$ gonadal disorders of sex development (DSD). We designed a synthetic probe set that targets genes within the 9p23-9p24.3 region and analyzed a group of $X Y$ patients with impaired gonadal development. We characterized a deletion distal to the DMRT genes in a patient with isolated $46, X Y$ gonadal DSD and narrowed down the breakpoint in a patient with a 46,XY del(9)(p23) karyotype with gonadal DSD and mild symptoms of 9p deletion syndrome. The results are compared with other patients described in the literature, and new aspects of sex reversal and the $9 p$ deletion syndrome candidate regions are discussed.

European Journal of Human Genetics (2009) 17, 1439-1447; doi:10.1038/ejhg.2009.70; published online 6 May 2009

Keywords: disorders of sex development (DSD); gonadal dysgenesis; sex reversal; multiple ligation-dependent probe amplification (MLPA); DMRT

\section{Introduction}

The $9 p$ distal region has been extensively investigated to identify genes involved in sex development because of the

*Correspondence: Dr M Barbaro, Department of Molecular Medicine and Surgery, Karolinska Institutet, Karolinska University Hospital, CMM L8:02, 17176 Stockholm, Sweden.

Tel: + 468 51774643; Fax + 46851773620 ;

E-mail: Michela.barbaro@ki.se

Received 19 December 2007; revised 3 March 2009; accepted 29 March 2009; published online 6 May 2009 observation of patients with the $9 p$ deletion syndrome, including abnormal sex development. Patients with the $9 \mathrm{p}$ deletion syndrome present with mental retardation, craniofacial dysmorphic features (eg, trigonocephaly, long philtrum) and delayed motor development, ${ }^{1}$ and in patients with XY chromosomes genital and/or gonadal disorders are quite frequent. Furthermore, in XY patients the disorders of sex development (DSD) have a wide spectrum of presentation. The external genital phenotype ranges from complete female to male with hypospadias. 
The gonadal phenotype ranges from complete gonadal dysgenesis to ovotestes and to cryptorchid and/or hypoplastic testis. The identification of 9p24 deletions in patients with XY gonadal dysgenesis but without typical $9 p$ deletion syndrome features, and the detection of patients with interstitial 9p deletions, has allowed the identification of two distinct regions for $9 p$ sex reversal and for the $9 \mathrm{p}$ deletion syndrome. The latter has been localized at $9 \mathrm{p} 22.3-\mathrm{p} 23,{ }^{2-6}$ whereas the sex reversal region has been progressively narrowed down to the region $9 \mathrm{p} 24.3$, extending from the DMRT genes to the telomere (Figure 1a). ${ }^{7-10}$ Within this region the strongest candidate genes for the gonadal dysgenesis phenotype are the DMRT genes that encode proteins with a DM domain. This is a zinc-finger-like DNA-binding motif that derives its name from the Drosophila doublesex (dsx) and the Caenorhabditis elegans mab-3 genes where it was initially identified. ${ }^{11}$ Both these genes are involved in downstream pathways of sex determination. There are three DMRT genes on 9p24, namely DMRT1, DMRT3 and DMRT2 (Figure 1). ${ }^{12,13}$ All deletions reported so far in patients with XY gonadal dysgenesis include all three genes, except for one case where the deletion is telomeric of the DMRT genes in a potential regulatory region. ${ }^{10}$ The molecular mechanism that leads to gonadal dysgenesis is not clear and could be caused by haploinsufficiency of one or more genes in the deleted region, by unmasking of a recessive mutation on the other chromosome or by more complicated mechanisms. The haploinsufficiency mechanism is the most likely because despite several attempts no mutations in DMRT1
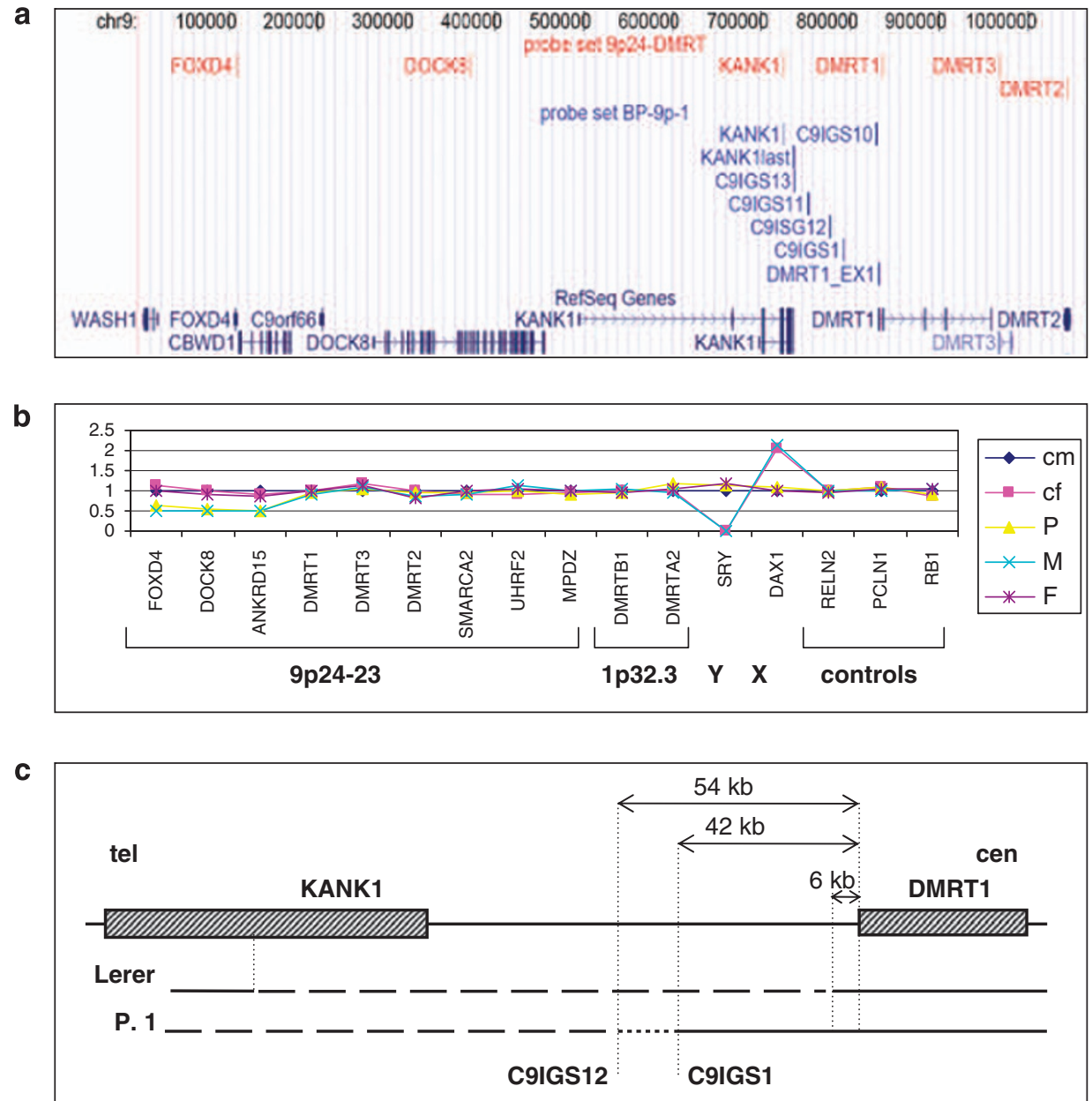

Figure 1 MLPA results for patient 1. (a) Representation from the UCSC genome browser of the 9p24.3 locus. Some of the probes included in the 9p24-DMRT probe sets and probes included in the BP-9p-1 set are represented by red and blue vertical lines, respectively. (b) Graph showing results of the MLPA analysis with the 9p24-DMRT probe set for patient $1(P)$ and her mother $(M)$ and father $(F)$, when normalized to the male control (cm). As expected the female control (cf) shows a double intensity for the DAX1 probe on chromosome $\mathrm{X}$. The patient and her mother show a deletion encompassing probes FOXD4, DOCK and KANK1, whereas her father has a pattern similar to the controls. Probe names are indicated along the $x$-axis and ratio values along the $y$-axis. (c) Schematic representation and comparison of the deletions at 9p24.3 carried by the subjects described by Lerer et $a l^{24}$ and patient 1 (P.1). Dashed lines represent the deleted regions, and dotted lines correspond to the breakpoint region. 
or DMRT2 have been identified. ${ }^{10,12,13}$ The DMRT3 gene was only recently described and no mutation screening has been reported so far. Furthermore, gene dosage imbalances of other genes are known to affect male gonadal development, involving for example SF1, NROB1 (DAX1), WT1, WNT4 and SOX9. It is not clear if haploinsufficiency of one or a combination of the DMRT genes is responsible for the phenotype. Dmrt1 ${ }^{-/-}$mice have been reported and they presented with hypoplastic testis but not with sex reversal. ${ }^{14}$ These results confirm that the DMRT1 gene is involved in sex development also in mammals and differences in the severity of the phenotype between murine and human abnormal sex development are not surprising. However, as 9p24.3 deletions have shown a noncomplete penetrance in patients, we still do not know if a single DMRT1 haploinsufficiency leads to gonadal dysgenesis or if other factors can modulate the phenotype.

The identification and fine mapping of submicroscopic distal or interstitial deletions on 9p24.3 would help to define the minimal sex reversal region and could lead to the identification of gene(s) responsible of the $46, \mathrm{XY}$ gonadal DSD. Until now 9p deletions were mostly detected by conventional karyotyping, and were caused by both distal deletions and unbalanced chromosome translocations. Screening for submicroscopic deletions has been performed by FISH or microsatellite analysis, but both these techniques have limited resolution. Lately array-CGH (comparative genomic hybridization) has been introduced in clinical practice thus improving the resolution.

Multiple ligation-dependent probe amplification (MLPA) represents an easy and reliable technique for detection of copy number variations and does not require parental samples for the evaluation of the results. We developed a probe set for MLPA analysis to detect deletions and duplications of genes on 9p24 in the region surrounding the suggested candidate genes for gonadal dysgenesis. Two additional probe pairs were designed within the DMRTB1 and DMRTA2 genes, which are located on chromosome band 1p32.3. These DMRT genes were chosen because they both show high expression in the adult human testis and have weak or absent expression in the adult ovary. ${ }^{15}$ Moreover, duplication of 1p31-p32.3 has been reported in some cases of $46, \mathrm{XY}$ DSD. ${ }^{16,17}$ Interestingly, the related dmrta2 in the Tilapia fish maps in a quantitative trait locus region for sex determination. ${ }^{18}$

Here, we report the results obtained from the analysis of 24 patients with $46, \mathrm{XY}$ testicular DSD.

\section{Subjects and methods}

Samples selected for this study were collected from patients that had been referred for $46, \mathrm{XY}$ gonadal DSD to the Clinical Genetic Unit of Karolinska University Hospital, Stockholm, Sweden, or to the Molecular Genetic Labora- tory of the Pediatric Unit at the S. Orsola-Malpighi Hospital, Bologna, Italy. The 12 patients (including one pair of siblings) from Sweden had 46,XY gonadal dysgenesis and female external genitalia with no signs of virilization. Abnormal gonadal development was diagnosed by the presence of female internal genitalia, very high levels of FSH and gonad biopsies, when available. The 10 Italian patients formed a more heterogeneous group of 46 , XY patients with abnormal gonadal development without a genetic diagnosis; the external genitalia ranged from completely female to ambiguous. Informed consents were collected. The study was approved by the regional ethics committee at the Karolinska Institutet. DNA was obtained from blood samples, EBV-immortalized cell lines or gonadal fibroblasts, when available. SRY gene mutations were excluded in all cases, as well gene dosage imbalances for SF1, SOX9, DAX1 and WNT4 genes. ${ }^{19}$ None of these 22 patients have $9 \mathrm{p}$ deletion syndrome. We also included a patient with a 46,XY karyotype and a deletion of approximately $700 \mathrm{~kb}$ at the $9 \mathrm{p}$ telomere previously detected by tiling BAC array-CGH (data not shown) and a patient with a 46,XY $\operatorname{del}(9)(\mathrm{p} 23)$ karyotype, both with gonadal dysgenesis.

\section{Controls}

Blood samples were collected anonymously from five fertile males and five healthy postpubertal females. Lymphocytes were isolated and EBV immortalized. DNA was extracted from the cell lines by phenol/chloroform extraction. Control DNA samples were also obtained from Karolinska University Hospital blood donors.

\section{Cases histories}

Patient 1 has been previously described as patient RB by Calvari et al. ${ }^{10}$ She has a 46,XY karyotype, and isolated complete gonadal dysgenesis with consequent female external genitalia.

Patient 2 was delivered by cesarean section at term due to fetal stress (Apgar 8-9), after an uncomplicated pregnancy. Birth weight and length were $3750 \mathrm{~g}$ and $49 \mathrm{~cm}$, respectively. The newborn presented normal female external genitalia. At 6 months of age she was referred to a pediatric neuropsychiatric unit because of mild developmental delay. She sat independently at 11 months, started walking at 20 months and spoke her first words at 24 months of age. She showed persisting developmental delay and hypotonia. Mild facial dysmorphism was present with methopic prominence, brachycephaly, flat nasal bridge, epicanthic folds, long philtrum and posteriorly rotated ears but no trigonocephaly. In addition, she had bifid uvula, high and narrow palate, webbed neck and a broad chest. Genetic evaluation revealed a 46,XY karyotype, and at the age of 6.8 years, she was further investigated by a pediatric endocrinologist. She presented female external genitalia, with mild hypoplasia of minor and major labia and no 
signs of virilization. Height was at the third percentile and the dysmorphic features as described above. A pelvic ultrasound examination showed the presence of a uterus with bilaterally visible gonadal tissue. A GnRH test $(50 \mu \mathrm{g}$ i.v.) showed pathological results with basal FSH and LH values of $44.3 \mathrm{mU} / \mathrm{ml}$ (reference values for prepubertal males $1.6 \pm 1.05$ and prepubertal females $3.1 \pm 1.8 \mathrm{mU} / \mathrm{ml}$ ) and $2.5 \mathrm{mU} / \mathrm{ml}$ (reference values for prepubertal males $0.82 \pm 0.64$ and prepubertal females $0.65 \pm 0.55 \mathrm{mU} / \mathrm{ml}$ ), and peak values of 130.2 and $37.3 \mathrm{mU} / \mathrm{ml}$, respectively. An hCG stimulation test (2000 UI i.m. for 3 days) was performed. Blood samples were analyzed after 3, 5 and 6 days. Basal and peak values for estradiol were 66.1 and $117.6 \mathrm{pmol} / \mathrm{l}$ (basal reference values $12.5 \pm 8.4 \mathrm{pmol} / \mathrm{l}$ ), for testosterone 1.0 and $0.7 \mathrm{nmol} / \mathrm{l}$ (basal and after stimulation normal values $0.6 \pm 0.02$ and $>3.1 \mathrm{nmol} / \mathrm{l}$ ), for D4-androstenedione 1.6 and $2.2 \mathrm{nmol} / \mathrm{l}$ (basal normal values $1.17 \pm 0.66 \mathrm{nmol} / \mathrm{l})$, for dehydroepiandrosterone 3.5 and $1.2 \mathrm{nmol} / \mathrm{l}$, and for $17-\mathrm{OHP} 1.2$ and $2.4 \mathrm{nmol} / \mathrm{l}$ (normal values $1.2 \pm 0.82 \mathrm{nmol} / \mathrm{l})$. Further cytogenetic studies on peripheral lymphocytes showed a 46,XY,del(9)(p23) karyotype in all 42 metaphases examined. The same result was achieved on 100 metaphases from gonadal fibroblast obtained after gonad biopsy. Histological examination of multiple biopsies from the left gonad showed the presence of fibrovascular tissue with Müllerian glandular-tubular structures. No normally differentiated testicular structure was seen, confirming the diagnosis of complete XY gonadal dysgenesis. No histological information is available for the right gonad. Prophylactic bilateral gonadectomy was performed. The patient is raised as a female and she will be treated with estrogen substitutive therapy as she approaches pubertal age. A conventional karyotype at 550 bands excluded balanced translocations in the parents.

\section{MLPA}

Synthetic probes for MLPA were designed as previously described. ${ }^{20,21}$ Probes targeting specific genes were designed within or at least partially covering the coding region. In addition, three control probes hybridizing to RELN, CLDN16 and RB1 genes located at chromosomes 7q22.1, 3q28 and 13q14.2, respectively, were included together with a 'pilot' probe pair to filter noise (Tables 1 and 2). The MLPA reactions were carried out, starting from $100 \mathrm{ng}$ of genomic DNA, and using the in-house designed probe set and the reagents from the EK1 reagent kit (MRCHolland, Amsterdam, the Netherlands), according to the manufacturer's recommendations. PCR products were separated using capillary electrophoresis system on an ABI 3100 genetic analyzer (Applied Biosystems). Trace data were analyzed using the GeneMapper version 3.7 software, and the integrated peak areas were exported to an Excel 2003 spreadsheet (Microsoft) for further calculations. For each sample, the peak areas were first normalized to the average peak area of the three control probes, followed by normalization to the average peak area of the control

Table 1 9p24-DMRT probe set used for MLPA analysis

\begin{tabular}{|c|c|c|c|c|c|}
\hline $\begin{array}{l}\text { Probe name } \\
\text { MIX 9p24 }\end{array}$ & Size & $5^{\prime}$ Half probe $^{\mathrm{a}}$ & $3^{\prime}$ Half probe $^{\mathrm{b}}$ & UCSC position ${ }^{\mathrm{C}}$ & $\begin{array}{l}\text { Chromsome } \\
\text { band }\end{array}$ \\
\hline GABRA4 (pilot) & 84 & CAGCCTGTTGTCATAACCATCG & AGCAAACTGTCCAGGATGCG & $46689618-46689659$ & $4 \mathrm{p} 12$ \\
\hline RELN (control) & 87 & CAGCATTACGGAATGAAGGTCA & CCACAAGAAGTGGCTTCACAACC & $102919656-102919700$ & $7 q 22.1$ \\
\hline FOXD4 & 90 & GGAGAGGAGGAAGATGAAGACGAGG & AGGAGGCGGCGAGCCAGCAGTTC & $107982-108029$ & $9 \mathrm{p} 24.3$ \\
\hline DMRT2 & 93 & GGAAACAGAATAATTTCGAGCGCA & AAGCTGTGTACCAGAGGCAAGTCAGAG & $1043741-1043791$ & $9 \mathrm{p} 24.3$ \\
\hline DOCK8 & 96 & GCTACCACACGTATGGCCGCACATCA & GCTGCTGCTGTGAGTTCAAAGCTGCTGC & $372543-372596$ & $9 \mathrm{p} 24.3$ \\
\hline KANK1 & 99 & CTGCAAACACСАTССССАGTGTGTACAA & AGTGCATGAGTGGGTTCATTGTCAAGGCC & $724847-724903$ & 9p24.3 \\
\hline DAX1 & 102 & GCAGCCTCAGCGGGCCTGTTGAAGACGCTG & СGCTTCGTCAAGTACTTGCССТGCTTCCAG & $30236574-30236633$ & $\mathrm{Xp21.2}$ \\
\hline $\begin{array}{l}\text { CLDN16 } \\
\text { (control) }\end{array}$ & 105 & GACACAAGGGTGTAAAATGCACG & $\begin{array}{l}\text { TITCAGGGTGTGTTTGCATATGATTTAATCAA } \\
\text { TCAGTATG }\end{array}$ & $191610505-191610567$ & $3 q 28$ \\
\hline DMRT1 & 108 & CAGTGCGGCCGAGCTGCTTGTCAAAAGAGAGAA & CAATGGCAGTAACCCGTGCСTCATGACTGAGTG & $837025-837090$ & $9 \mathrm{p} 24.3$ \\
\hline DMRT3 & 111 & CTCAAGGGCCACAAGCGTTACTGCCGCTTCA & $\begin{array}{l}\text { AGGACTGCACCTGCGAGAAGTGCATCCTCA } \\
\text { TCATCGAG }\end{array}$ & $967122-967190$ & $9 p 24.3$ \\
\hline DMRTB1 & 114 & $\begin{array}{l}\text { CTGCGAGAAGTGCTACCTGATCTCCGAGC } \\
\text { GCCAGA }\end{array}$ & $\begin{array}{l}\text { AGATCATGGCCGCGCAGAAGGTGCTCAAGAC } \\
\text { GCAGGC }\end{array}$ & $53697822-53697893$ & $1 \mathrm{p} 33$ \\
\hline DMRTA2 & 117 & $\begin{array}{l}\text { CACGTITTCTCСССТCССAGAGGCCAAGTTGCA } \\
\text { GAAGT }\end{array}$ & $\begin{array}{l}\text { TTGACCTGTTTCCTAAGACGCTGCTGCAGG } \\
\text { CAGGCCG }\end{array}$ & $50657939-50658013$ & $1 \mathrm{p} 32.3$ \\
\hline SRY & 120 & $\begin{array}{l}\text { GAATGCGAAACTCAGAGATCAGCAAGC } \\
\text { AGCTGGGA }\end{array}$ & $\begin{array}{l}\text { TACCAGTGGAAAATGCTTACTGAAGCCGAA } \\
\text { AAATGGCCATTCG }\end{array}$ & $2715318-2715394$ & Yp11.31 \\
\hline MPDZ & 123 & $\begin{array}{l}\text { GTGATCCAGTACTTGATCTGCATATGTCTCTGGAG } \\
\text { GAACT }\end{array}$ & $\begin{array}{l}\text { ATATACCCAGAATCTCCTGCAAAGACAGGATG } \\
\text { AGAATACAC }\end{array}$ & $13166317-13166397$ & $9 p 23$ \\
\hline SMARCA2 & 126 & $\begin{array}{l}\text { GAAAGGATTCGTAATCATAAGTACCGGAGCCTAGG } \\
\text { CGACCTGGAG }\end{array}$ & $\begin{array}{l}\text { AAGGATGTCATGCTTCTCTGTCACAACGCTC } \\
\text { AGACGTTC }\end{array}$ & $2172141-2172224$ & $9 p 24.3$ \\
\hline RB1 (control) & 129 & $\begin{array}{l}\text { GTCACCAATACCTCACATTCCTCGAAGCCCTT } \\
\text { ACAAGTTTCCT }\end{array}$ & $\begin{array}{l}\text { AGTTCACCCTTACGGATTCCTGGAGGGAACAT } \\
\text { CTATATTTCACC }\end{array}$ & $47937353-47937439$ & $13 q 14.2$ \\
\hline UHRF2 & 132 & $\begin{array}{l}\text { GTACGAGAGAATGTACTATTGTCCCTTCTAATCA } \\
\text { TTATGGACCCATTC }\end{array}$ & $\begin{array}{l}\text { CTGGTATTCCTGTTGGATCAACTTGGAGATTT } \\
\text { AGAGTTCAGG }\end{array}$ & $6472011-6472100$ & $9 p 24.1$ \\
\hline
\end{tabular}

${ }^{a}$ The $5^{\prime}$ half probes are preceded by the universal tag sequence GGGTTCCCTAAGGGTTGGA.

'The $3^{\prime}$ half probes are followed by the universal tag sequence TCTAGATTGGATCTTGCTGGCAC and are phosphorylated at the $5^{\prime}$-end.

'UCSC assembly: May 2006; numbers indicate the coordinate of the $5^{\prime}$ half probe first base and the 3 ' half probe last base. 
Table 2 BP-9p-1 and BP-9p-2 probe sets used for MLPA analysis

\begin{tabular}{|c|c|c|c|c|c|}
\hline Probe name & Size & $5^{\prime}$ Half probe $^{a}$ & $3^{\prime}$ Half probe $^{b}$ & UCSC position ${ }^{c}$ & $\begin{array}{l}\text { Chromsome } \\
\text { band }\end{array}$ \\
\hline \multicolumn{6}{|l|}{$M I X \quad B P-9 p-1$} \\
\hline GABRA4 (pilot) & 84 & CAGCСТGTTGTCATAACCATCG & AGCAAACTGTCCAGGATGCG & $46689618-46689659$ & 4p12 \\
\hline RELN (control) & 87 & CAGCATTACGGAATGAAGGTCA & CCACAAGAAGTGGCTTCACAACC & $102919656-102919700$ & $7 q 22.1$ \\
\hline C9IGS1 & 93 & GTGCTGTGGCCTCATCCCAGGAAGTA & GCAAGTCAACTGTATCCAATGAGGG & $791605-791654$ & $9 \mathrm{p} 24.3$ \\
\hline KANK1 last & 96 & GCTCCGTTITGTACAGTCACAGGGAA & ТTCTGATCTGAAGGGGCACСТTCTGTTC & $735482-735535$ & \\
\hline KANK1 & 99 & CTGCAAACACCATCCCСAGTGTGTACAA & AGTGCATGAGTGGGTTCATTGTCAAGGCC & $724847-724903$ & $9 \mathrm{p} 24.3$ \\
\hline DMRT1ex1 & 102 & CCTAGGGGCACCATGCCCAACGACGAGGCATT & CAGCAAGCCCTCTACACCGTCGGAAGCC & $831827-831886$ & 9 p24.3 \\
\hline $\begin{array}{l}\text { CLDN16 } \\
\text { (control) }\end{array}$ & 105 & GACACAAGGGTGTAAAATGCACG & $\begin{array}{l}\text { TITCAGGGTGTGTTTGCATATGATTTAATCAA } \\
\text { TCAGTATG }\end{array}$ & $191610505-191610567$ & $3 q 28$ \\
\hline C9IGS12 & 108 & САGTGATTTAATCCATAATAAGGGAGAGTCT & GCTCAGTTTITAGGGAATTTCAATGAAGTTGATTC & $776889-776954$ & 9 p24.3 \\
\hline C9IGS11 & 111 & ССTGTTGAAAGCCACTCAATGGCTTCAGCTCGGT & CTGGCATGATGAAGCTTCCTCCGTAATCTGGGTTC & $752281-752349$ & $9 \mathrm{p} 24.3$ \\
\hline C9IGS10 & 117 & $\begin{array}{l}\text { GGAGAGAAAGGAGACAACAAAGCCAGGCTACT } \\
\text { TGAAATATC }\end{array}$ & CAGTACAAATTTGTTCATTCTTGGGGCCTTCCTG & $828029-828103$ & $9 \mathrm{p} 24.3$ \\
\hline C9IGS13 & 123 & $\begin{array}{l}\text { GCAGCAACAGACCAGCTCTCCCAGGACCACAAG } \\
\text { GATGACTIT }\end{array}$ & $\begin{array}{l}\text { ССТСТGCATGAACTGTGAAAGTGAGGTCACAGC } \\
\text { САССTG }\end{array}$ & $737115-737195$ & \\
\hline $\begin{array}{l}\text { RB1 ex23 } \\
\text { (control) }\end{array}$ & 129 & $\begin{array}{l}\text { GTCACCAATACCTCACATTCCTCGAAGCCCTTA } \\
\text { CAAGTTCCT }\end{array}$ & $\begin{array}{l}\text { AGTTCACCCTTACGGATTCCTGGAGGGAACATC } \\
\text { TATATTTCACC }\end{array}$ & $47937353-47937439$ & $13 q 14.2$ \\
\hline \multicolumn{6}{|l|}{$M I X B P-9 p-2$} \\
\hline GABRA4 (pilot) & 84 & CAGCCTGTTGTCATAACCATCG & AGCAAACTGTCCAGGATGCG & $46689618-46689659$ & $4 p 12$ \\
\hline RELN & 87 & CAGCATTACGGAATGAAGGTCA & CCACAAGAAGTGGCTTCACAACC & $102919656-102919700$ & $7 q 22.1$ \\
\hline PTPRD & 90 & CAGCGAGTCTGTCCGATCTGAAAT & TTCAGCTGGAACACTTTCAGAGCC & $8723900-8723947$ & $9 p 24.1$ \\
\hline DAX1 & 102 & GCAGCCTCAGCGGGCCTGTTGAAGACGCTG & СGСТTCGTCAAGTACTTGСССТGCTTCCAG & $30236574-30236633$ & $\mathrm{Xp} 21.2$ \\
\hline $\begin{array}{l}\text { CLDN16 } \\
\text { (control) }\end{array}$ & 105 & GACACAAGGGTGTAAAATGCACG & $\begin{array}{l}\text { TITCAGGGTGTGTITGCATATGATTTAATCAAT } \\
\text { CAGTATG }\end{array}$ & $191610505-191610567$ & $3 q 28$ \\
\hline C9IGS11 & 108 & $\begin{array}{l}\text { GGTGAAACACTGAATACTTTCTTCCACATA } \\
\text { TCAGGAC }\end{array}$ & AACAATGGAGATGTGAGGTCTCACCACTG & $11354381-11354445$ & $9 p 23$ \\
\hline TYRP1 & 111 & $\begin{array}{l}\text { GCTCAATTCCCAAGACAGTGTGCCACT } \\
\text { GTTGAGGCTT }\end{array}$ & TGAGAAGTGGTATGTGTTGCCCAGACCTGTCC & $12684066-12684134$ & $9 p 23$ \\
\hline JMJD2C & 114 & $\begin{array}{l}\text { GCCGAGGTGGAAAGTCCTCTGAACCCCAGCTG } \\
\text { TAAGAT }\end{array}$ & АATGACСTTCAGACССТCСATGGAGGAGTTCCGG & $6782998-6783069$ & $9 p 24.1$ \\
\hline SRY & 120 & $\begin{array}{l}\text { GAATGCGAAACTCAGAGATCAGCAAGCAGC } \\
\text { TGGGA }\end{array}$ & $\begin{array}{l}\text { TACCAGTGGAAAATGCTTACTGAAGCCGAAAA } \\
\text { ATGGCCATTCG }\end{array}$ & $2715318-2715394$ & Yp11.31 \\
\hline MPDZ & 123 & $\begin{array}{l}\text { GTGATCCAGTACTTGATCTGCATATGTCTCTG } \\
\text { GAGGAACT }\end{array}$ & $\begin{array}{l}\text { ATATACCCAGAATCTCCTGCAAAGACAGGATGA } \\
\text { GAATACAC }\end{array}$ & $13166317-13166397$ & $9 p 23$ \\
\hline C9IGS12 & 126 & $\begin{array}{l}\text { GGATTTATCTCTTCTTCAAGTCTGTTGGCCTITTT } \\
\text { GAACATGGACGT }\end{array}$ & $\begin{array}{l}\text { AAATGTCCTTCCTCAGATTTGGGAAGATTGGGT } \\
\text { CACG }\end{array}$ & $11547281-11547363$ & $9 p 23$ \\
\hline $\begin{array}{l}\text { RB1 ex23 } \\
\text { (control) }\end{array}$ & 129 & $\begin{array}{l}\text { GTCACCAATACCTCACATTCCTCGAAGCCCTTA } \\
\text { CAAGTTTCCT }\end{array}$ & $\begin{array}{l}\text { AGTTCACCCTTACGGATTCCTGGAGGGAACATC } \\
\text { TATATTTCACC }\end{array}$ & $47937353-47937439$ & $13 q 14.2$ \\
\hline ÜHRF2 & 132 & $\begin{array}{l}\text { GTACGAGAGAATGTACTATTGTCCCTTCTAATCAT } \\
\text { TATGGACCCATTC }\end{array}$ & $\begin{array}{l}\text { CTGGTATTCCTGTTGGATCAACTTGGAGATTTA } \\
\text { GAGTTCAGG }\end{array}$ & $6472011-6472100$ & $9 \mathrm{p} 24.1$ \\
\hline
\end{tabular}

${ }^{2}$ The $5^{\prime}$ half probes are preceded by the universal tag sequence GGGTTCCCTAAGGGTTGGA.

'The $3^{\prime}$ half probes are followed by the universal tag sequence TCTAGATTGGATCTTGCTGGCAC and are phosphorylated at the $5^{\prime}$-end.

'UCSC assembly: May 2006; numbers indicate the coordinate of the 5 ' half probe first base and the 3 ' half probe last base.

samples included in the run. The analysis was considered acceptable if the ratio for the internal control was between 0.8 and 1.2. Threshold values for deletion and duplication were set at 0.75 and 1.25 , respectively.

\section{Results}

\section{MLPA analysis}

The performance of the 9p24-DMRT probe set (Table 1) was tested using DNA samples from 10 normal controls (5 males and 5 females). All probes presented an SD $\leq 10 \%$ thus proving to be reliable and sufficiently consistent. A total of 22 patients were analyzed. Deletions were confirmed in the two cases with the 9p24 deletions already identified by other methods, but no other deletions or duplications were detected.

In patient 1 , a deletion of approximately $700 \mathrm{~kb}$ at 9p24.3 had been identified using a 33K tiling BAC arrayCGH (unpublished data). No other rearrangements have been identified in the patient. The MLPA analysis con- firmed the deletion of three subtelomeric genes FOXD4, DOCK8 and KANK1 (previously known as ANKRD15), whereas the probe located within the DMRT1 gene did not show a deletion. Analysis of parental DNA showed that the mother is the healthy carrier of the deletion (Figure 1). After this finding we received more information about the patients and came to know that this patient had been previously studied by Calvari et al. ${ }^{10}$ The deletion breakpoint had been mapped in a region of $30 \mathrm{~kb}$ upstream the DMRT1 gene. To further narrow down the breakpoint and in particular to evaluate if the DMRT1 promoter was deleted we designed an additional MLPA probe set BP-9p1 (Table 2). We determined that the deletion extends until probe C9IGS12, located $54 \mathrm{~kb}$ upstream of the DMRT1 gene, whereas the region detected by the probe C9IGS1 is still present in two copies, indicating that at least $42 \mathrm{~kb}$ of the DMRT1 promoter is still present.

In patient 2 , the deletion extended from the probe pair located within the UHRF2 gene to the most telomeric probe pair within FOXD4 (Figure 2b). All probes within this 
a

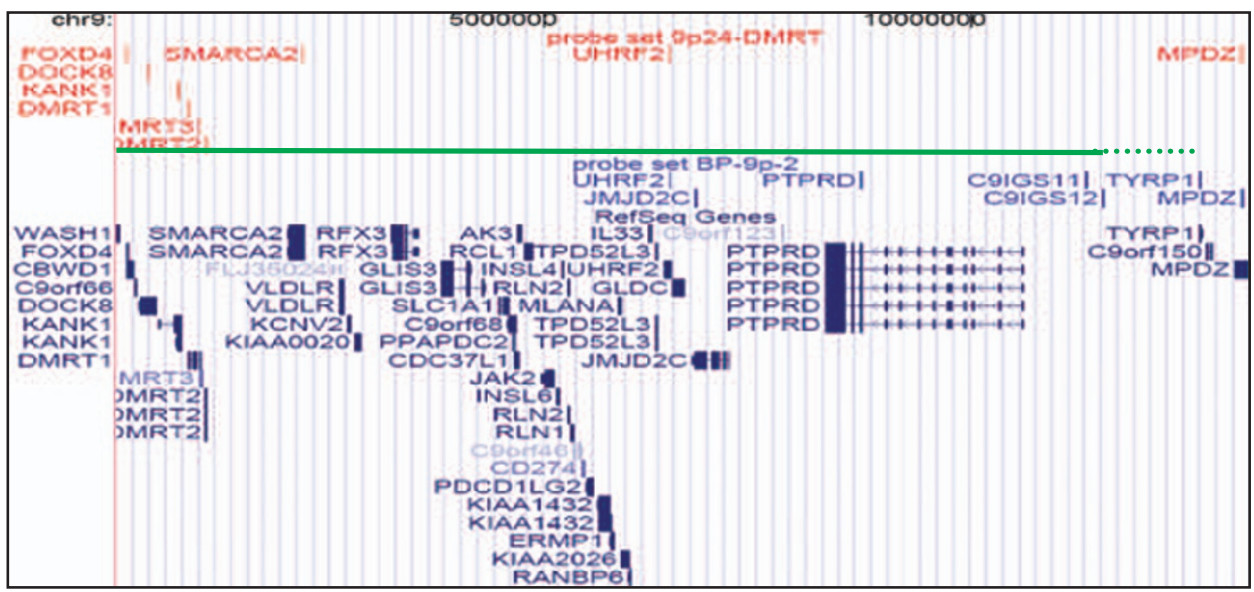

b

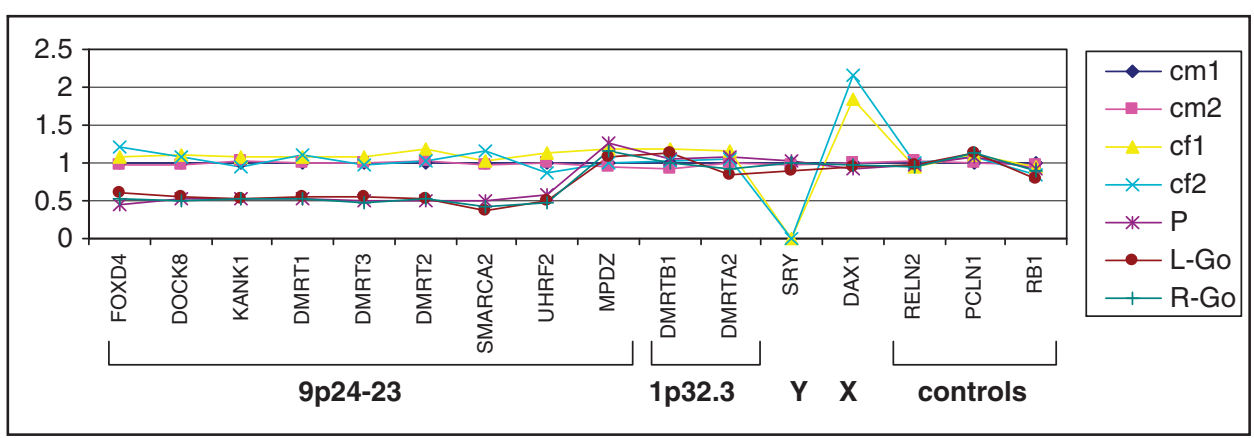

Figure 2 MLPA results for patient 2. (a) Representation from the UCSC genome browser of the 9p24-p23 region. The location of probes included in the 9p24-DMRT and BP-9p-2 probe sets is represented by red and blue vertical lines, respectively. The green line represents the deleted region with the breakpoint region indicated by dotted line. (b) Graph showing the results for patient 2 when normalized to male controls (cm) using the $9 \mathrm{p} 24-$ DMRT set. As expected the female controls (cf) shows a double intensity for the DAX1 probe on chromosome X. DNA obtained from a blood sample (P) and fibroblasts from left and right gonads (L-Go and R-Go) show a deletion extending from the telomeric probe pair FOXD4 to the probe pair UHRF2, whereas the MPDZ probe pair has a ratio value corresponding to two copies of the gene as well as the probe pairs on $1 \mathrm{p} 32.3$.

region had a ratio below the threshold that was set to 0.75 , with a median value of 0.51 (range $0.34-0.54$ ), near the theoretical value of 0.5 . The probe located in the MPDZ gene had a ratio consistent with two copies. Genomic DNA derived from the fibroblasts obtained from bilateral gonad biopsies was analyzed and the genetic alteration was confirmed in the gonadal tissue (Figure $2 \mathrm{~b}$ ). We designed the BP-9p-2 probe set (Table 2) to further narrow down the breakpoint region by MLPA. The distal deletion extended for at least $11.5 \mathrm{Mb}$, until the probe C9IGS12, whereas the more centromeric probe TYRP1, located within the first coding exon of the TYRP1 gene, had a ratio value consistent with two copies of the gene.

As some of the target genes in the 9p24-DMRT probe set are listed in the database of genomic variants ${ }^{22}$ (http:// projects.tcag.ca/variation/), we also analyzed 68 healthy controls (36 males and 32 females) to evaluate the frequency of such polymorphisms in the Swedish population. No copy number variations were detected.

\section{Discussion}

The candidate region for sex reversal on $9 p$ has been narrowed down to the 9p24.3 region. Even if it is not clear which gene(s) and genetic mechanisms are involved in the impairment of gonadal development, the major candidate genes are DMRT1 and DMRT3. Mice with a targeted deletion of Dmrt1 have shown postnatal testis defects, thus proving the function of DMRT1 in mammalian sexual differentiation. ${ }^{14}$ As the dmrt1 deficiency was not sufficient to cause sex reversal, the concomitant haploinsufficiency of the conserved downstream DMRT3 gene may be necessary for a more severe disruption of gonadal development. Dmrt2 knockout mice have been recently described. ${ }^{23}$ They show embryonic somite patterning defects and no sex development impairments, thus making DMRT2 haploinsufficiency less likely as the cause of gonadal dysgenesis. ${ }^{23}$ As 9p24.3 is located in the subtelomeric region of $9 p$, small deletions can easily escape detection by karyotyping using conventional banding 
techniques. We therefore developed an MLPA probe set covering this region to screen for submicroscopic deletions, or duplications, in patients with $46, \mathrm{XY}$ testicular dysgenesis. Probes were designed within the three DMRT genes, in three more telomeric genes FOXD4, DOCK 8 and KANK1 and three centromeric genes SMARCA2, UHRF2 and MPDZ outside the candidate gonadal dysgenesis region (Figures $1 \mathrm{a}$ and 2a). The MLPA analysis with the 9p24-DMRT probe set readily detected the two already identified deletions on 9 p24, proving to be a reliable method. Unfortunately, no deletions were identified in other patients with 46,XY DSD neither for genes at 9p24 nor for the DMRT genes on the 1 p32.3 region.

In patient 1 , who has an isolated $46, \mathrm{XY}$ gonadal DSD, the small distal deletion that does not include the DMRT genes gives rise to many hypotheses and considerations in favor and against DMRT haploinsufficiency as the cause of gonadal dysgenesis. A study from $2005^{24}$ reported a deletion that extends from within the KANK1 gene to approximately $6.5 \mathrm{~kb}$ upstream the DMRT1 gene (Figure 1c), which segregates in a large pedigree of patients affected by familial cerebral palsy. Among the carriers there are three males that are fathers, indicating that a deletion of this region does not affect male sex development or fertility. Thus, if DMRT1 expression is required for testis development, $6.5 \mathrm{~kb}$ of the DMRT1 promoter is sufficient for its function. In patient 1 more than $40 \mathrm{~kb}$ of the promoter region is still present, which suggests that DMRT1 expression is retained and that the GD phenotype is not due to DMRT1 haploinsufficiency. The gonadal phenotype could instead be caused by haploinsufficiency of one of the more telomeric genes. Another possibility, which we believe is more likely, is that in patient 1 the distal deletion locates the DMRT1 gene in proximity of the telomere and this could affect the expression of DMRT1 even if the regulatory region is intact. ${ }^{25}$

Although additional patients with 9p24 deletions and $46, X Y$ gonadal dysgenesis have been identified, ${ }^{26-30}$ at the same time patients with 9p24 deletions and normal male external genitalia and/or very mild gonadal abnormalities have also been described. ${ }^{6,31,32}$

We believe that a DMRT defect is involved in the gonadal dysgenesis phenotype, however a more complicated mechanism should be hypothesized, to explain the variable penetrance. One possibility could be that the DMRT haploinsufficiency together with other genetic defects would lead to gonadal dysgenesis through a dosage threshold effect. Interestingly, five copy number variants (CNVs) affecting DMRT1 are listed in the Database of Genomic Variants. ${ }^{33-36}$ The data are however not sufficient to consider a DMRT1 deletion as a CNV polymorphism. Other genes important for gonadal development that act in a dosage manner are listed in the database, for example, NROB1 (DAX1), WT1 and SOX9. This indicates also that the information contained in the
Database of Genomic Variants should be carefully interpreted when evaluating regions involved in sex development; CNVs for autosomal genes may cause a sex development defect only in subjects with XY chromosomes and be carried by healthy fertile XX subjects, or vice versa.

The different type of genetic rearrangements leading to $9 p$ deletions that could affect gene expression in a different manner, and the apparent non-full penetrance of the phenotype shown by the patients make it very difficult to understand the genetic and molecular mechanism leading to DSD. Furthermore, for some XY patients genital ambiguities are reported without any information about the gonadal development, which is fundamental to distinguish between a defect of gonadal development or a defect only of external genitalia development, which are caused by different mechanisms.

In patient 2 , the telomeric deletion, already identified by conventional karyotyping, extends for $11.5 \mathrm{Mb}$ and the breakpoint is located within a $1.1 \mathrm{Mb}$ region between the probe C9IGS12 and the probe TYRP1, located in the first exon of the TYRP1 gene.

A recent study has clearly divided the patients with $9 p$ deletions in two groups. One group includes patients with the consensus phenotype of $9 \mathrm{p}$ deletion syndrome (trigonocephaly, small palpebral fissures, flat nasal bridge with anteverted nostrils, long philtrum and micro/retrognathia), whereas the other group includes patients that, although they carry $9 \mathrm{p}$ deletions, do not meet all the criteria of the consensus phenotype, in particular they lack trigonocephaly. Patient 2 does not present with trigonocephaly, thus she belongs to the latter group; however, she has metopic prominence and other dysmorphic features. In fact, the deletion breakpoint is telomeric to the critical region for $9 p$ deletion syndrome recently described by Swinkels et al, ${ }^{6}$ which has been obtained by comparing the genetic rearrangements in the two groups of patients. We noticed that some patients had distal deletions whereas others had interstitial deletions. The breakpoint in patient 2 is located in the region between the most distal and the most centromeric breakpoints carried by patients without trigonocephaly described by Swinkels et al (Figure 3); however, it is not stated if these patients had other cranial dysmorphologies and/or metopic prominence. We have carefully searched the literature to identify patients with clear molecular characterization and phenotype to compare with patient 2 . We identified two patients with a mild 9 p deletion syndrome presenting with prominent forehead and a 9p deletion breakpoint distal to the Swinkels' critical region 32,37 (Figure 3). Furthermore, a patient with a complex rearrangement with a distal 9p24 deletion but a duplication on 9p12-p23 is described to have XY gonadal DSD but no dysmorphic features. ${ }^{7}$ We believe that there is a region, distal to Swinkels' critical region, that should still be carefully taken into account when genotype-pheno- 


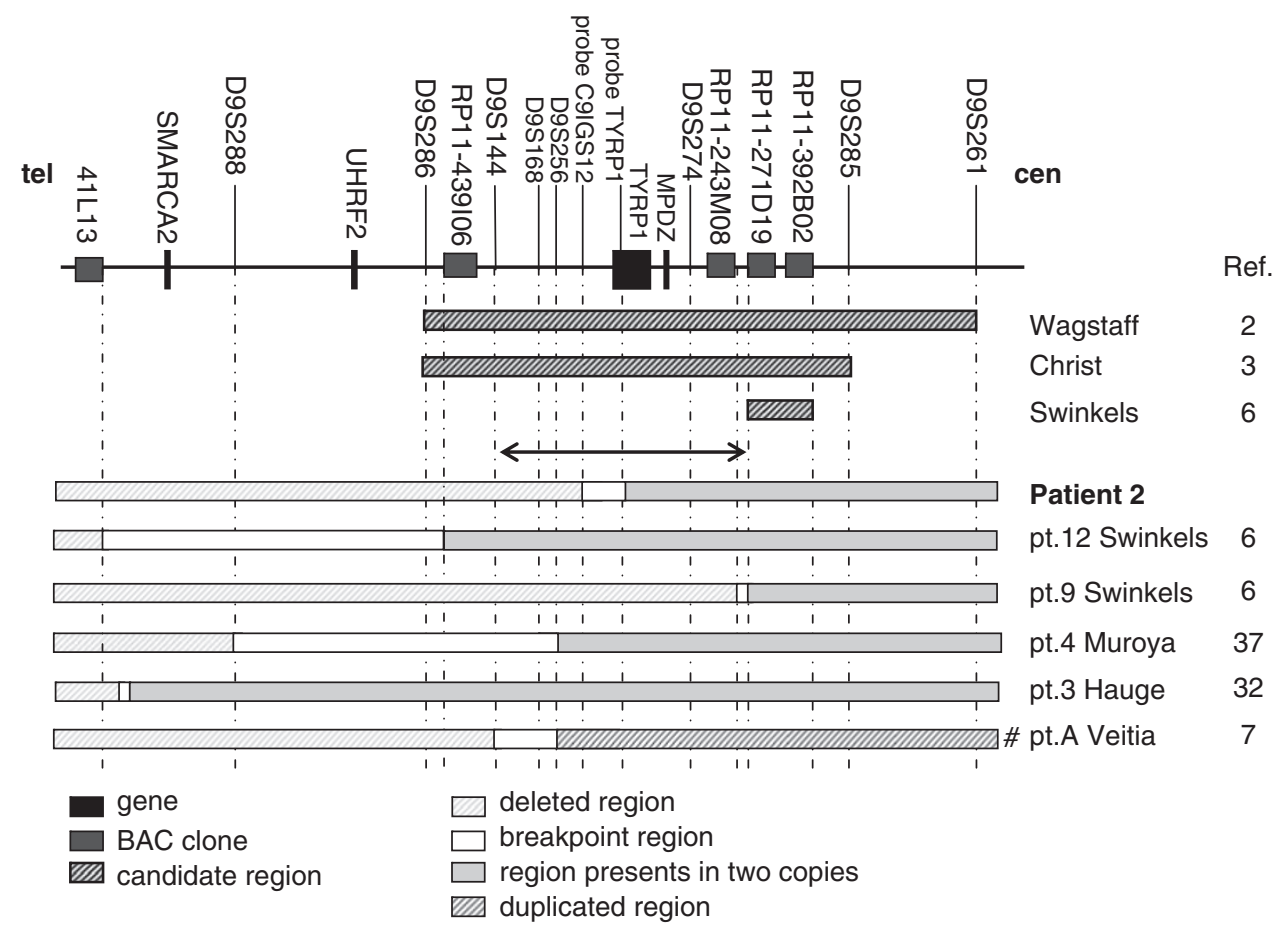

Figure 3 Critical region for the $9 p$ deletion syndrome. Molecular characterization of critical $9 p$ deletion regions and of different patients is compared. All patients have a mild form of the 9p deletion syndrome except the one labeled with a \# symbol that has isolated 46,XY gonadal DSD. Black arrows indicate the region that should still be taken into account for a genotype-phenotype correlation of dysmorphic features in patients with $9 p$ deletions. The chromosomal region is not drawn to scale; only selected genes are represented as black boxes.

type correlation for $9 p$ deletion syndrome is evaluated (Figure 3). The mild cranial dysmorphism in patients with deletion distal to the critical region could be caused either by misregulation of the candidate gene for trigonocephaly or by the deletion of other gene(s) involved in craniofacial development.

Correlation between genotype and phenotype has proven to be difficult in patients with $9 \mathrm{p}$ deletion. As the region is near the telomere and the loss of material can be due to several types of rearrangements, it is fundamental to compare patients with and without a phenotypical characteristic and to have a highly refined molecular characterization. Furthermore, determination of a minimal critical region using only patients with distal deletion should be avoided as positional effects are difficult to evaluate and the results could be completely different when patients with interstitial deletions are included and compared, as shown by the different conclusions in Hauge et $a l^{32}$ compared to Swinkels et al. ${ }^{6}$

To conclude, the MLPA-based analysis of all patients with $46, \mathrm{XY}$ gonadal dysgenesis or other $46, \mathrm{XY}$ testicular DSD, and even patients with $9 \mathrm{p}$ deletion syndrome, would lead to the identification and rapid characterization of more patients with rearrangements on $9 \mathrm{p} 24$. The accurate genetic characterization of a sufficient number of patients together with a detailed clinical description, as well as a morphological and molecular examination of gonadal tissue, would represent the starting point for identifying the molecular mechanisms that lead to each characteristic of the phenotype.

\section{Acknowledgements}

We thank Dr Jacqueline Shoumans for fruitful scientific discussion, Dr Paola Biso for help in the cytogenetic investigation and Dr Laura Mazzanti for phenotype specifications. This work was supported by the Stiftelsen Frimurare Barnhuset (to MB); the Fredrik and Ingrid Thuring Foundation, the Magn. Bergvall Foundation and the Swedish Society of Medicine (to MO); the Swedish Research Council (Grant No. 12198), the Novo Nordisk Foundation, Karolinska Institutet and the Stockholm County Council (to $A W$ ).

\section{References}

1 Huret JL, Leonard C, Forestier B, Rethore MO, Lejeune J: Eleven new cases of del(9p) and features from 80 cases. J Med Genet 1988; 25: $741-749$.

2 Wagstaff J, Hemann M: A familial 'balanced' 3;9 translocation with cryptic $8 \mathrm{q}$ insertion leading to deletion and duplication of 9p23 loci in siblings. Am J Hum Genet 1995; 56: 302-309.

3 Christ LA, Crowe CA, Micale MA, Conroy JM, Schwartz S: Chromosome breakage hotspots and delineation of the critical region for the 9p-deletion syndrome. Am J Hum Genet 1999; 65: $1387-1395$. 
4 Kawara $\mathrm{H}$, Yamamoto $\mathrm{T}$, Harada $\mathrm{N}$ et al: Narrowing candidate region for monosomy $9 \mathrm{p}$ syndrome to a $4.7-\mathrm{Mb}$ segment at 9p22.2-p23. Am J Med Genet A 2006; 140: 373-377.

5 Faas BH, de Leeuw N, Mieloo H, Bruinenberg J, de Vries BB: Further refinement of the candidate region for monosomy $9 p$ syndrome. Am J Med Genet A 2007; 143: 2353-2356.

6 Swinkels ME, Simons A, Smeets DF et al: Clinical and cytogenetic characterization of 13 Dutch patients with deletion 9p syndrome: delineation of the critical region for a consensus phenotype. $A m J$ Med Genet A 2008; 146A: 1430-1438.

7 Veitia R, Nunes $M$, Brauner $R$ et al: Deletions of distal 9p associated with $46, \mathrm{XY}$ male to female sex reversal: definition of the breakpoints at 9p23.3-p24.1. Genomics 1997; 41: 271-274.

8 Flejter WL, Fergestad J, Gorski J, Varvill T, Chandrasekharappa S: A gene involved in XY sex reversal is located on chromosome 9, distal to marker D9S1779. Am J Hum Genet 1998; 63: 794-802.

9 Guioli S, Schmitt K, Critcher R et al: Molecular analysis of 9p deletions associated with XY sex reversal: refining the localization of a sex-determining gene to the tip of the chromosome. Am J Hum Genet 1998; 63: 905-908.

10 Calvari V, Bertini V, De Grandi A et al: A new submicroscopic deletion that refines the $9 \mathrm{p}$ region for sex reversal. Genomics 2000; 65: 203-212.

11 Raymond CS, Shamu CE, Shen MM et al: Evidence for evolutionary conservation of sex-determining genes. Nature 1998; 391: 691-695.

12 Raymond CS, Parker ED, Kettlewell JR et al: A region of human chromosome $9 p$ required for testis development contains two genes related to known sexual regulators. Hum Mol Genet 1999; 8: 989-996.

13 Ottolenghi C, Veitia R, Quintana-Murci L et al: The region on 9p associated with $46, \mathrm{XY}$ sex reversal contains several transcripts expressed in the urogenital system and a novel doublesex-related domain. Genomics 2000; 64: 170-178.

14 Raymond CS, Murphy MW, O'Sullivan MG, Bardwell VJ, Zarkower D: Dmrt1, a gene related to worm and fly sexual regulators, is required for mammalian testis differentiation. Genes Dev 2000; 14: 2587-2595.

15 Ottolenghi C, Fellous M, Barbieri M, McElreavey K: Novel paralogy relations among human chromosomes support a link between the phylogeny of doublesex-related genes and the evolution of sex determination. Genomics 2002; 79: 333-343.

16 Garcia-Heras J, Corley N, Garcia MF, Kukolich MK, Smith KG, Day DW: De novo partial duplications 1p: report of two new cases and review. Am J Med Genet 1999; 82: 261-264.

17 Wieacker P, Volleth M: WNT4 and RSPO1 are not involved in a case of male-to-female sex reversal with partial duplication of $1 \mathrm{p}$. Sex Dev 2007; 1: 111-113.

18 Shirak A, Seroussi E, Cnaani A et al: Amh and Dmrta2 genes map to tilapia (Oreochromis spp.) linkage group 23 within quantitative trait locus regions for sex determination. Genetics 2006; 174: $1573-1581$.

19 Barbaro M, Cicognani A, Balsamo A et al: Gene dosage imbalances in patients with $46, \mathrm{XY}$ gonadal DSD detected by an in-housedesigned synthetic probe set for multiplex ligation-dependent probe amplification analysis. Clin Genet 2008; 73: 453-464.

20 Stern RF, Roberts RG, Mann K, Yau SC, Berg J, Ogilvie CM: Multiplex ligation-dependent probe amplification using a completely synthetic probe set. Biotechniques 2004; 37: 399-405.
21 Barbaro M, Oscarson M, Schoumans J, Staaf J, Ivarsson SA, Wedell A: Isolated $46, \mathrm{XY}$ gonadal dysgenesis in two sisters caused by a Xp21.2 interstitial duplication containing the DAX1 gene. J Clin Endocrinol Metab 2007; 92: 3305-3313.

22 Iafrate AJ, Feuk L, Rivera MN et al: Detection of largescale variation in the human genome. Nat Genet 2004; 36: 949-951.

23 Seo KW, Wang Y, Kokubo H, Kettlewell JR, Zarkower DA, Johnson RL: Targeted disruption of the DM domain containing transcription factor Dmrt2 reveals an essential role in somite patterning. Dev Biol 2006; 290: 200-210.

24 Lerer I, Sagi M, Meiner V, Cohen T, Zlotogora J, Abeliovich D: Deletion of the ANKRD15 gene at 9p24.3 causes parent-of-origindependent inheritance of familial cerebral palsy. Hum Mol Genet 2005; 14: 3911-3920.

25 Ottaviani A, Gilson E, Magdinier F: Telomeric position effect: from the yeast paradigm to human pathologies? Biochimie 2008; 90: 93-107.

26 Vialard F, Ottolenghi C, Gonzales $\mathrm{M}$ et al: Deletion of 9p associated with gonadal dysfunction in $46, \mathrm{XY}$ but not in $46, \mathrm{XX}$ human fetuses. I Med Genet 2002; 39: 514-518.

27 Livadas S, Mavrou A, Sofocleous C, van Vliet-Constantinidou C, Dracopoulou M, Dacou-Voutetakis C: Gonadoblastoma in a patient with $\operatorname{del}(9)(\mathrm{p} 22)$ and sex reversal: report of a case and review of the literature. Cancer Genet Cytogenet 2003; 143: $174-177$.

28 Witters I, Vermeesch JR, Moerman PH, Fryns JP: Partial trisomy $3 \mathrm{p} /$ monosomy $9 \mathrm{p}$ with sex reversal. Ultrasound Obstet Gynecol 2004; 23: 418-419.

29 Ounap K, Uibo O, Zordania R et al: Three patients with 9p deletions including DMRT1 and DMRT2: a girl with XY complement, bilateral ovotestes, and extreme growth retardation, and two XX females with normal pubertal development. Am J Med Genet A 2004; 130: 415-423.

30 Vinci G, Chantot-Bastaraud S, El Houate B, Lortat-Jacob S, Brauner R, McElreavey K: Association of deletion 9p, 46,XY gonadal dysgenesis and autistic spectrum disorder. Mol Hum Reprod 2007; 13: 685-689.

31 Hayashi S, Kurosawa K, Imoto I, Mizutani S, Inazawa J: Detection of cryptic chromosome aberrations in a patient with a balanced $\mathrm{t}(1 ; 9)(\mathrm{p} 34.2 ; \mathrm{p} 24)$ by array-based comparative genomic hybridization. Am J Med Genet A 2005; 139: 32-36.

32 Hauge X, Raca G, Cooper S et al: Detailed characterization of, and clinical correlations in, 10 patients with distal deletions of chromosome 9p. Genet Med 2008; 10: 599-611.

33 Mills RE, Luttig CT, Larkins CE et al: An initial map of insertion and deletion (INDEL) variation in the human genome. Genome Res 2006; 16: 1182-1190.

34 Levy S, Sutton G, Ng PC et al: The diploid genome sequence of an individual human. PLoS Biol 2007; 5: e254.

35 Korbel JO, Urban AE, Affourtit JP et al: Paired-end mapping reveals extensive structural variation in the human genome. Science 2007; 318: 420-426.

36 Redon R, Ishikawa S, Fitch KR et al: Global variation in copy number in the human genome. Nature 2006; 444: 444-454.

37 Muroya K, Okuyama T, Goishi K et al: Sex-determining gene(s) on distal 9p: clinical and molecular studies in six cases. J Clin Endocrinol Metab 2000; 85: 3094-3100. 